\title{
Obstructive sleep apnea syndrome: how should the dental surgeon proceed?
}

\author{
Apnéia obstrutiva do sono: como o cirurgião-dentista deve proceder?
}

\author{
Maiara Medeiros RONSANI \\ Thiago Martins MEIRA² \\ Luiz Roberto GODOLFIM ${ }^{3}$ \\ Roberto Ramos GARANHANI ${ }^{4}$
}

\begin{abstract}
The aim of this study is to describe a case report of obstructive sleep apnea syndrome and to describe a logical sequence for the treatment of patients who suffer from this disease. Through an interpretation of the polysomnography examination, case history, and clinical examination and by performing cephalometric analysis for sleep apnea, a safe and effective treatment using an intraoral device was indicated. Along these lines, a mandibular advancement device, the Posicionador Luiz Godolfim (PLG), was constructed. After using the device for 4 weeks, the patient underwent another polysomnography, which showed the absence of obstructive sleep apnea. The steps followed for the treatment in this case highlight the importance of and the need for a correct and careful approach for patients with sleep apnea referred to dental office. The approach and sequence presented ensured the success of treatment in this case.
\end{abstract}

Indexing terms: Mandibular advancement. Polysomnography. Sleep apnea syndrome.

\section{RESUMO}

O presente trabalho tem por objetivo relatar um caso clínico diagnosticado como Síndrome da apnéia obstrutiva do sono, e expor uma sequência lógica para o tratamento de pacientes que sofrem desta doença. Através da interpretação do exame de polissonografia, da anamnese, exame clínico e, ainda, por meio da realização do traçado e análise cefalométrica para apnéia do sono, indicou-se de forma segura e efetiva a terapia com aparelho intra-oral. Desta maneira, foi confeccionado um aparelho de avanço mandibular, o PLG. Após quatro semanas de uso do aparelho, o paciente foi encaminhado à realização de uma nova polissonografia, a qual revelou ausếncia de apnéias obstrutivas durante o sono. As etapas seguidas no tratamento deste estudo de caso destacaram a importância e a necessidade de uma abordagem correta e criteriosa dos casos de pacientes com apnéia do sono encaminhados ao consultório odontológico. A abordagem e sequência apresentadas garantiram o sucesso no tratamento deste estudo de caso.

Termos de indexação: Avanço mandibular. Polissonografia. Síndromes da apnéia do sono.

\section{INTRODUCTION}

The recognition of respiratory disorders during sleep has been increasing each year in the field of medicine, and it has aroused the interest of dentistry in obstructive sleep apnea syndrome (OSAS), the most common of these disorders, which affects $4 \%$ of middle-aged men and $2 \%$ of middle-aged women'.

OSAS is considered to be a major public health issue $^{2}$ and is a chronic condition characterized by recurrent episodes of obstruction of the upper airways (UA) during sleep, leading to a significant reduction (hypopnea) or total blockage (apnea) of the airflow for at least $10 \mathrm{~s}$. These events occur because of the collapse of pharyngeal tissues, resulting from the combination of a reduction in the muscle tone of the tongue and pharynx, changes in respiratory control, the supine position, and decreased pharyngeal space in susceptible individuals ${ }^{3}$.
Obstructive episodes are usually accompanied by loud snoring and a drop in blood oxygen saturation (hypoxemia), ending in short micro-awakenings, which result in sleep fragmentation ${ }^{4}$. Sleep basically consists of two moments that alternate between waking states: non-rapid eye movement (NREM) and rapid eye movement (REM). Sleep apnea events last longer and have higher hypoxemia during REM sleep than during NREM sleep in patients with OSAS .

According to Jauhar et al. ${ }^{2}$, the deterioration of sleep quality caused by OSAS significantly contributes to excessive daytime sleepiness, loss of cognitive capacity, and mood swings and personality changes. It has also been associated with a worsening in the quality of life and in relationships with spouses and partners, decreased alertness, and an increased risk of traffic accidents. In addition, there are indications of an increase in cardiovascular diseases among untreated OSAS patients, and it is a potentially life-threatening condition ${ }^{1,3,6-7}$ that requires an early diagnosis and effective treatment.

\footnotetext{
${ }^{1}$ Universidade do Estado da Bahia, Departamento de Educação. Av. Vanessa Cardoso \& Cardoso, s/n, Ipanema, 46430-000, Guanambi, BA, Brasil. Correspondência para / Correspondence to: MM RONSANI. E-mail: <maiaraorto@gmail.com.br>.

${ }^{2}$ Universidade do Estado da Bahia, Departamento de Educação, Guanambi, BA.

${ }^{3}$ Hospital de Aeronáutica de Canoas, Departamento de Ortodontia e Ortopedia Facial. Canoas, SC, Brasil.

${ }^{4}$ Universidade do Sul de Santa Catarina, Curso de Odontologia. Tubarão, SC, Brasil.
} 
Polysomnography (PSG) is considered to be the gold standard among diagnostic exams for OSAS. Conducted in a sound lab where the patient is monitored while he/she sleeps, it records several variables over a period of time. The minimum required tests recorded are the electroencephalogram (EEG), electrooculogram (EOG), and submental electromyogram (EMG). Additional parameters are required for an evaluation of sleep-related respiratory disorders such as nasal-oral airflow, in addition to oximetry (which measures arterial oxygen saturation), electrocardiogram, snore and body position sensors, and an electromyogram of the legs ${ }^{8}$.

According to the American Academy of Sleep Medicine (AASM), a diagnosis of OSAS is established when PSG detects the occurrence of at least five apnea and/or hypopnea events/h of sleep, expressed through the Apnea and Hypopnea Index (AHI). This index also classifies the degree of severity of OSAS according to the following scale: 5 to 15 , mild; 15 to 30 , moderate; and $>30$, severe. Hypopneas are only considered in the AHI calculation when there is a $>50 \%$ reduction in the airflow, accompanied by $>3 \%$ blood oxygen desaturation or micro-awakenings ${ }^{9}$. In addition to checking $\mathrm{AHI}$, the existence of clinical signals related to excessive daytime sleepiness, loud snoring, and other signs and symptoms related to sleep apnea should be considered during diagnosis and treatment.

According to Strobel \& Rosen ${ }^{10}$, obesity is a significant risk factor related to the development of OSAS or an increase in its severity. Fat deposits around the neck tend to narrow the pharyngeal region, increasing the possibility of UA collapse. The body mass index (BMI) is the product of a calculation related an individual's weight and height, indicating an overweight condition. Other OSAS risk factors such as alcohol consumption ${ }^{11}$ and smoking ${ }^{12}$ need to be considered because they produce greater muscle relaxation, facilitating the occurrence of collapse. The position of the body while sleeping also influences the frequency of apnea and hypopnea. In many cases, $\mathrm{AHI}$ increases in dorsal decubitus and decreases in the lateral position ${ }^{13}$.

Since the elucidation of the physiopathology of OSAS, cephalometric analyses have revealed that compared with healthy individuals, patients affected by OSAS have craniofacial differences ${ }^{14}$. In 1991, Rintala et al. ${ }^{15}$ reported on points, planes, angles, and linear measurements most commonly used in cephalometric tracings of patients with OSAS. The usually found characteristics are mandibular retrognathia in relation to the cranial base and maxilla, a greater than normal perpendicular distance from the hyoid bone to the mandibular plane, and a longer and thicker soft palate than that of healthy individuals. Battagel \& L'Estrange ${ }^{3}$ also confirmed that the dimensions of the retropalatal space of the oropharynx are significantly reduced and the tongue is proportionately wider. According to the authors, these factors cause narrowing of UAs, which may be aggravated by the degenerative relaxation of the soft tissues that occurs with increasing age, and they are most pronounced in the supine position during the overall relaxation of sleep.

Treatment of OSAS is primarily based on the degree of severity indicated by AHI, which must be considered together with the clinical signs and symptoms, any existing morbid consequences, clinical and radiographical craniofacial characteristics, and the condition of the mouth as well as any added risk factors such as obesity, smoking, and alcohol consumption.

The main non-invasive treatments described in the literature are continuous positive airway pressure (CPAP) and intraoral devices (IODs). The former is a therapeutic method for treating all levels of OSAS. It consists of a nasal mask connected to a motor that pumps air at a positive and continuous pressure, opening UA and preventing the collapse of the pharyngeal tissues. IODs are a relatively recent development, being indicated more often for mild to moderate cases of OSAS $2,16-19$.

IODs are divided into two types: a) tongue retainer devices, proposed by Cartwright \& Samelson ${ }^{20}$, which hold the tongue in a more forward position, promoting better opening of UAs, and b) mandibular advancement devices (MADs), which keep the jaw protruding, increasing the dimension of UAs, including the hypopharynx, oropharynx, and nasopharynx. This action improves the airflow and reduces the possibility of respiratory blockage ${ }^{21}$.

Both CPAPs and IODs are effective in relieving symptoms, improving excessive daytime sleepiness, quality of life, and several aspects of neurocognitive function in patients with $\mathrm{AHI}$ from 5 to $30^{22}$. Although CPAP is extensively used in the treatment of OSAS, some patients are reluctant to use them or are unable to tolerate them, preferring IODs ${ }^{23}$

In this context, dentistry has been increasingly responsible for treating cases of OSAS that have been prescribed IODs. The growing need of dentists experienced in performing this treatment method enlarges the scope for these professionals because they specialize and recognize the need for a correct and careful approach for patients with OSAS who are referred to the dental clinic.

The aim of this study is to describe a case report of OSAS and to describe a logical sequence for the treatment of patients who suffer from this disease. 


\section{CASE REPORT}

This study was approved by the Research Ethics Committee, with protocol number 08.284.4.02.III. A male patient (46 years old, married, non-smoker, occasional alcohol drinker) who was diagnosed with OSAS was complaining of a lack of concentration, daytime sleepiness, and irritability. His wife reported that his extremely heavy snoring was negatively affecting their relationship. The patient's BMI was 29.4, classified as overweight (BMI between 25.0 and 29.9). In the PSG report, AHI of 17.6 was noted, with apneas and hypopneas, a predominance of obstructive events during REM sleep (39.6 events/h), snoring during $31.2 \%$ of the total sleep time (TST), mostly dorsal decubitus, minimum blood oxygen saturation of $89 \%$, micro-awakening index of 14.2 events/h, and sleep efficiency of $90.1 \%$. No significant electroencephalographic or electrocardiographic changes were observed.

The clinical examination confirmed the presence of 24 teeth (Figure 1) with good periodontal support and no mobility of the elements. The patient was not undergoing dental treatment or intending to begin any prosthetic planning. The patient reported no pain. Teleradiography of the profile was requested, and cephalometric tracing and analysis for sleep apnea were performed.

After evaluation of the values obtained in the cephalometric tracing (Table 1), the presence of a higher number of favorable than unfavorable measurements was considered for performing therapy using IOD.

Two impressions were made of both the upper and lower jaws to obtain study and work models. The work models were associated by means of an occlusal registration using the George Gauge ${ }^{24}$ (Great Lakes Orthodontics, Tonawanda, USA) together with sheets of

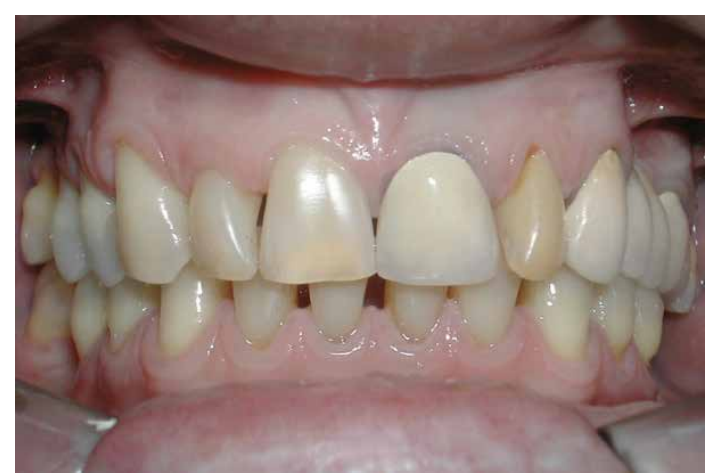

Figure 1. Intraoral view

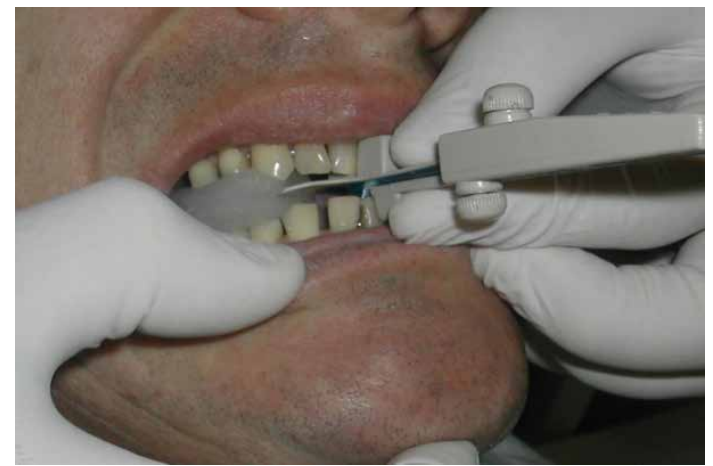

Figure 2. Registration of the interocclusal relationship using the George Gauge and wax \#7 sheet

white wax \#7 (Epoxiglass, Diadema, Brazil). A maximum protrusion (MP) of $11 \mathrm{~mm}$ was measured using this device. The possible mandibular advancement for IOD, which should be $80 \%$ of MP, was then calculated ${ }^{25}$, equivalent to $8.8 \mathrm{~mm}$ in this case. The George Gauge was attached in this new position, wrapped in a sheet of wax in the area of the occlusal fork, and placed between the jaws of the patient, who was instructed to bite down slowly (Figure 2).

Table 1. Values obtained following cephalometric tracing for sleep apnea Florianópolis (SC), 2008.

\begin{tabular}{|c|c|c|c|c|}
\hline Factor & Male Standard masculino & Female Standard feminino & Average & Evaluation \\
\hline Anterior cranial base (SNa) & $80.0 \pm 2$ & $73.0 \pm 3$ & 80.0 & Normal \\
\hline Maxillary length (Ans-Pns) & $62.5 \pm 4$ & $54.0 \pm 3$ & 50.0 & Decreased \\
\hline Mandibular body length (Goc-Me) & $84.5 \pm 5$ & $74.0 \pm 5$ & 79.0 & Decreased \\
\hline Atlas-maxillary distance (A-Pns) & $36.0 \pm 3.5$ & $36.0 \pm 3$ & 53.0 & Increased \\
\hline Upper pharyngeal airway (Upphw-PP1) & $26.0 \pm 4$ & $24.0 \pm 3.5$ & 28.5 & Normal \\
\hline Posterior mid-palatal airway (PP2-PP2 фॄ) & $12.0 \pm 3.5$ & $14.0 \pm 2$ & 13.5 & Normal \\
\hline Soft palate length (Enp-P) & $34.0 \pm 5$ & $35.0 \pm 4.5$ & 54.0 & Increased \\
\hline Mid-pharyngeal airway (Mpphw-Maphw) & $22.0 \pm 4.5$ & $21.0 \pm 3.5$ & 7.3 & Decreased \\
\hline Posterior air space (PAS) & $15.5 \pm 3.5$ & $13.0 \pm 2.5$ & 9.5 & Decreased \\
\hline Distance hyoid-C3 vertebra $(\mathrm{H}-\mathrm{C} 3)$ & $41.0 \pm 3.5$ & $36.0 \pm 3$ & 52.0 & Increased \\
\hline Distance hyoid-mandibular plane & $19.0 \pm 6$ & $15.0 \pm 3$ & 28.5 & Increased \\
\hline Tongue length (TGL) & $79.0 \pm 5$ & $72.5 \pm 3$ & 81.0 & Normal \\
\hline Tongue height (TGH) & $29.5 \pm 3$ & $24.0 \pm 3$ & 17.0 & Decreased \\
\hline Lower air space (LAS) & $17.5 \pm 4$ & $13.5 \pm 2$ & 8.0 & Decreased \\
\hline
\end{tabular}


A PLG device ${ }^{26}$ (Figure 3) was constructed, which enables gradual mandibular advancement through the activation of dorsal arches (Figure 4), freedom of lateral, protrusive movement, and stabilization of the mandible.

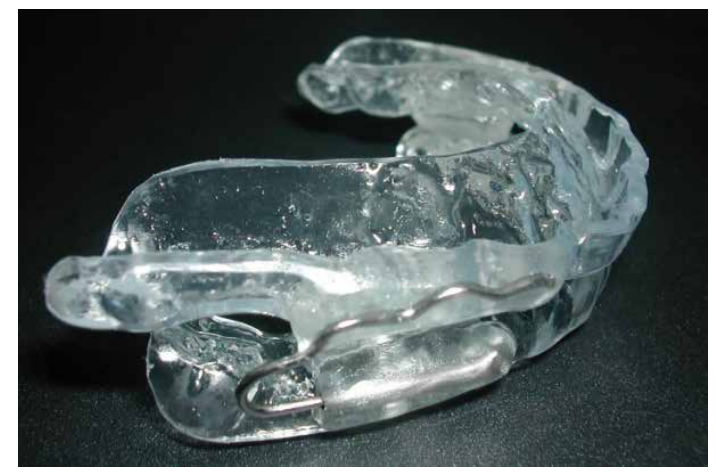

Figure 3. PLG device

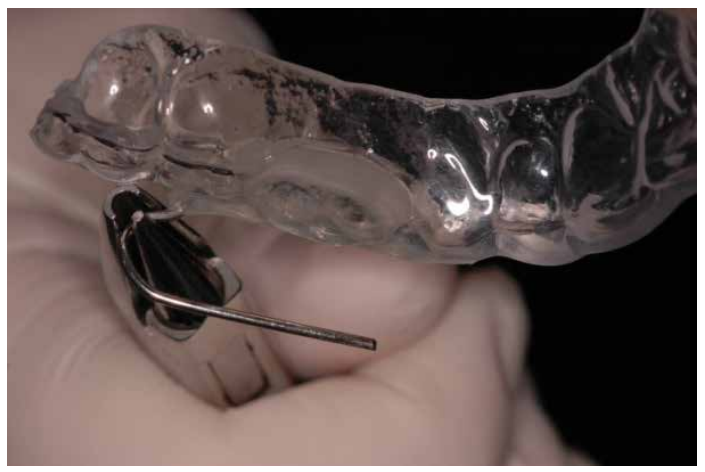

Figure 4. Activation of the dorsal arches

During the installation of the device (Figure 5), the patient received instructions about the use and maintenance of the device and was informed of the need for subsequent clinical follow-up.

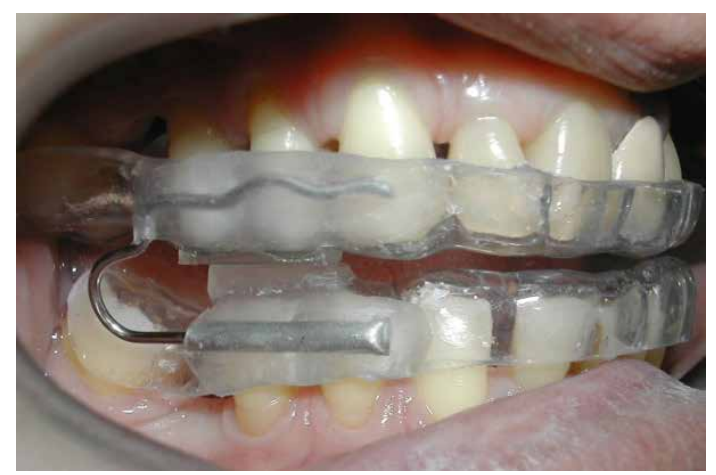

Figure 5. Installation of the device

Mandibular advancement was progressively performed in three subsequent sessions. The initial advancement of $7 \mathrm{~mm}^{25}$ was made after 1 week of use of the device. The additional advancements of $1 \mathrm{~mm}$ each were made at 15-day intervals.

After 4 weeks of using the device, the patient underwent another polysomnography, with the device in position this time.

The examination revealed $\mathrm{AHI}$ of 4.1 and an absence of apnea, with the majority of obstructive events occurring during REM sleep, although with a significant improvement (11.7 events/h). In addition, a reduction in the intensity, if not the percentage, of snoring was observed. Dorsal decubitus was predominant, minimum blood oxygen saturation was $90 \%$, the micro-awakening index was $10.7 / \mathrm{h}$, and sleep efficiency was $91.8 \%$. No significant electroencephalographic or electrocardiographic changes were observed. BMI remained the same following treatment with PSG.

The cephalometric radiograph, PSG data, study models, and photographs were archived for future reference and for use as control during follow-up appointments that would be conducted at 6-month intervals during the first year and annually thereafter.

This clinical study was conducted after clarification to the patient and the signing of an informed consent form.

\section{DISCUSSION}

According to AASM, the treatment goals for patients with apnea are resolution of the clinical signs and symptoms of apnea and normalization of $\mathrm{AHI}$ and blood oxygen saturation ${ }^{16}$. In this case, the main objectives described above were achieved. The main results were the improvement of clinical signs and symptoms, particularly in terms of the patient's daytime sleepiness and lack of concentration, and the reports of loud snoring made by his wife. The initial AHI of 17.6, representing a moderate level of apnea, fell to 4.1 (normal $<5$ events/h), and the saturation of oxyhemoglobin rose from $89 \%$ to $90 \%$, remaining practically stable, as demonstrated by the second polysomnograph with the device in position, a practice also recommended by $\mathrm{AASM}^{16}$.

Many studies have reported the use of IODs to treat mild ( $\mathrm{AHI}=5$ to 15$)$ and moderate $(\mathrm{AHI}=15$ to 30 ) OSAS, with proven short- and long-term efficacy ${ }^{2,17-19,27}$. It is important to emphasize that the dental surgeon must not base a decision regarding whether this device is the best treatment option for the patient solely on the basis of this index, even in cases where a referral already comes with this indication. Verifying the signs and signals, analyzing the PSG data, performing extraoral and intraoral 
examinations, requesting for profile cephalometric teleradiography, and analyzing the results, are important steps in detecting abnormalities and clinical factors that predispose to apnea and may contraindicate treatment with IODs. When these data are considered together with $\mathrm{AHI}$, there is a greater possibility of indicating the most effective treatment.

According to Hierl et al. ${ }^{14}$, a request for profile cephalometric radiography and subsequent analysis focused on obstructive sleep apnea should undoubtedly be included in the diagnosis-treatment protocol of OSAS. They observed that a short mandible, narrow posterior airway, long soft palate, and low positioning of the hyoid seem to be the most significant parameters encountered in patients with OSAS. According to Mayer \& MeierEwert ${ }^{28}$, these and other cephalometric findings specific to obstructive sleep apnea will act as indicators of the possibility of success with IODs.

In our case, the patient had a slightly decreased mandibular length (79.0 mm/Normal: $84.5 \mathrm{~mm} \pm 5$ ), increased soft palate length $(54.0 \mathrm{~mm} /$ Normal: $34.0 \mathrm{~mm} \pm$ $5)$, decreased posterior pharyngeal space $(9.5 \mathrm{~mm} /$ Normal: $15.5 \mathrm{~mm} \pm 3.5)$, and increased hyoid-mandibular plane distance ( $28.5 \mathrm{~mm} /$ Normal: $19.0 \mathrm{~mm} \pm 6$ ), indicating a lower positioning of the hyoid, corroborating the most commonly encountered cephalometric findings in patients who suffer from obstructive sleep apnea ${ }^{3,14}$. Of the values obtained by cephalometry in this case, the maxillary length and soft palate length were considered to be unfavorable to IOD therapy because they reduce the efficiency of the mode of action of the device. However, the other values were considered to be favorable to this treatment modality, which helped in the decision-making process.

MAD uses the teeth to anchor it in the mandibular protrusion, and according Johal \& Battage ${ }^{29}$, it increases the size of the airway, stretching the tongue and the soft palate forward and maintaining airflow in UA during sleep. However, MAD is not indicated in all cases, making a clinical examination necessary because according to Shoaf ${ }^{7}$, to retain the device, the patient must have at least eight healthy teeth in each jaw without the presence of active periodontal disease or increased movement of the teeth. In his study, he also states that patients with a history of temporomandibular dysfunction (particularly chronic pain) would not adapt to the device because the protrusive positioning can lead to a recurrence or increase in pain in the temporomandibular joint (TMJ).

Given the chronic nature of OSAS, the adverse effects of long-term treatment should be considered.
The study by Hammond ${ }^{17}$, in which 185 patients were interviewed before and after beginning treatment with $M A D$, corroborated prior studies, which found that adverse effects from the use of MAD over long periods of time are common, although they are mild and welltolerated by most patients. Almeida et al. ${ }^{6}$ observed favorable dental changes in almost half of the patients who had been using IODs for an average of 7.4 years. According to the results of Almeida et al. ${ }^{30}$, IODs induced teeth movement but no craniofacial skeletal changes. In 2005, because of existing concerns regarding adverse events, the Standards of Practice Committee of AASM published practical guidelines for treatment using IODs in patients with obstructive sleep apnea, in which they recommended follow-up every 6 months during the first year of treatment and annually thereafter ${ }^{16}$. According to these practical guidelines, the purpose of follow-up is to monitor adherence, evaluate deterioration of the device, adjust the device, assess the health of the structures of the mouth and the integrity of the occlusion, and determine whether the signs and symptoms of apnea have worsened.

Almeida et al. ${ }^{6}$ concluded that because the use of IODs for OSAS is a long-term treatment and because the changes appear to continue over time, archiving cephalometric radiographs, study models, and preand post-treatment intraoral photographs should be encouraged in all clinical protocols for the use of IODs.

\section{CONCLUSION}

The dental surgeon should not begin the treatment of referral patients with OSAS using IOD without checking the radiographic, clinical, and polysomnographic characteristics relevant to a correct indication of this therapy.

The case history, clinical examination, and analysis of the initial cephalometric and polysomnographic tests as well as subsequent request for and interpretation of a second polysomnographic examination (using IOD) are essential for the proper approach and follow-up of apneic patients.

The presented approach ensured successful treatment in this case.

\section{Acknowledgements}

The authors thank Dr. Fábio José Fabrício de Barros Souza for his helpfulness and collaboration in the selection of the patient for this study. 


\section{Collaborators}

MM RONSANI was responsible for writing the article and assisting during the study of the clinical

\section{REFERENCES}

1. Young T, Palta M, Dempsey J, Skatrud J, Weber S, Badr S. The occurrence of sleep disordered breathing among middle-paged adults. N Engl J Med. 1993;328(17):1230-5. doi: 10.1056/ NEJM199304293281704

2. Jauhar S, Lyons MF, Banham SW, Cameron DA, Orchardson R. Ten-year follow-up of mandibular advancement devices for the management of snoring and sleep apnea. J Prosthet Dent. 2008;99(4):314-21. doi: 10.1016/S0022-3913(08)60067-0

3. Battagel JM, L'Estrange PR. The cephalometric morphology of patients with obstructive sleep apnoea (OSA). Eur J Orthod. 1996;18(6):557-69. doi: 10.1093/ejo/18.6.557

4. Deegan PC, McNicholas WT. Pathophysiology of obstructive sleep apnoea. Eur Respir J. 1995;8(7):1161-78. doi: 10.1183/09031936.95.08071161

5. Findley LJ, Wilhoit SC, Suratt PM. Apnea duration and hypoxemia during REM sleep in patients with obstructive sleep apnea. Chest. 1985;87(4):432-6. doi: 10.1378/chest.87.4.432

6. Almeida FR, Lowe AA, Sung JO, Tsuiki S, Otsuka R. Longterm sequellae of oral appliance therapy in obstructive sleep apnea patients: Part 2. Study-model analysis. Am J Orthod Dentofacial Orthop. 2006;129(2):205-13. doi:10.1016/j. ajodo.2005.04.034

7. Shoaf SC. Sleep disorders and oral appliances: what every orthodontist should know. J Clin Orthod. 2006;40(12):719-22.

8. Indications and standards for cardiopulmonary sleep studies. American Thoracic Society. Medical Section of the American Lung Association. Am Rev Respir Dis. 1989;139(2):559-68. doi: 10.1164/ajrccm/139.2.559

9. Sleep-related breathing disorders in adults: recommendations for syndrome definitions and measurements techniques in clinical research. Sleep. 1999;22(5):667-89.

10. Strobel RJ, Rosen, RC. Obesity and weight loss in obstructive sleep apnea: a critical review. Sleep. 1996;19(2):104-15.

11. Scrima L, Broudy M, Nay KN, Cohn MA. Increased severity of obstructive sleep apnea after bedtime alcohol ingestion: diagnostic potential and proposed mechanism of action. Sleep. 1982;5(4):318-28

12 Phillips BA, Danner FJ. Cigarette smoking and sleep disturbance. Arch Intern Med. 1995;155(7):734-7. doi:10.1001/ archinte.1995.00430070088011 case. TM MEIRA reviewed and translated the article. LR GODOLFIM conducted the clinical study. RR GARANHANI reviewed and provided guidance to the article and photographic documentation.
13. Mador MJ, Kufel TJ, Magalang UJ, Rajesh SK, Watwe V, Grant BJB. Prevalence of positional sleep apnea in patients undergoing polysomnography. Chest. 2005;128(4):2130-7. doi:10.1378/ chest.128.4.2130

14. Hierl $T$, Hümpfner-Hierl $H$, Frerich $B$, Heisgen $U$, Bosse-Henck A, Hemprich A. Obstructive sleep apnoea syndrome: results of a principal component analysis. J Craniomaxillofac Surg. 1997;25(4):181-5. doi:10.1016/S1010-5182(97)80073-X

15. Rintala A, Nordstrom R, Partinen M, Ranta R, Sjoblad A. Cephalometric analysis of the obstructive sleep apnea syndrome. Proc Finn Dent Soc. 1999;87(1):177-82.

16. Kushida CA, Morgentheler TI, Littner M R, Alessi CA, Bailey $D$, Coleman J, et al. Practice parameters for the treatment of snoring and obstructive sleep apnea with oral appliances: an update for 2005. Sleep. 2006;29(2):240-3.

17. Hammond RJ, Gotsopoulos H, Shen G, Petocz P, Cistulli PA, Darendeliler MA. A follow-up study of dental and skeletal changes associated with mandibular advancement splint use in obstructive sleep apnea. Am J Orthod Dentofacial Orthop. 2007;132(6):806-14. doi:10.1016/j.ajodo.2005.08.047

18. Marklund M, Franklin KA. Long-term effects of mandibular repositioning appliances on symptoms of sleep apnoea. J Sleep Res. 2007;16(4):414-20. doi: 10.1111/j.13652869.2007.00615.x

19. Otsuka R, Almeida FR, Lowe AA. The effects of oral appliance therapy on occlusal function in patients with obstructive study. Am J Orthod Dentofacial Orthop. 2007;131(2):176-83. doi: 10.1016/j.ajodo.2005.03.028

20. Cartwright RD, Samelson CF. The effects of nonsurgical treatment for obstructive sleep apnea: the tongue-retaining device. JAMA. 1982;248(6):705-9. doi: 10.1001/jama.1982.03330060045032

21. Gale DJ, Sawyer RH, Woodcock A, Stone P, Thompson R, O'Brien K. Do oral appliances enlarge the airway in patients with obstructive sleep apnoea? A prospective computerized tomographic study. Eur J Orthod. 2000;22(2):159-68. doi: 10.1093/ejo/22.2.159

22. Barnes M, Mcevoy RD, Banks S, Tarquinho S, Murray CG, Vowles $\mathrm{N}$, et al. Efficacy of positive airway pressure and oral appliance in mild to moderate obstructive sleep apnea. Am J Respir Crit Care Med. 2004;170(6):656-64. doi: 10.1164/rccm.200311-15710C

23. Ferguson $K A$, Ono $T$, Lowe $A A$, Keenan $S$, Fleethan JA. $A$ randomized crossover study of an oral appliance vs nasalcontinuous positive airway pressure in the treatment of mildmoderate obstructive sleep apnea. Chest. 1996;109(5):126975. doi:10.1378/chest.109.5.1269 
24. George PT. A new instrument for functional appliance bite registration. J Clin Orthod. 1992;26(11):721-23.

25. Godolfim, LR. Os aparelhos orais no tratamento do ronco e apnéia do sono. In: Sakai E, Cotrim-Ferreira FA, Martins NS. Nova visão em ortodontia e ortopedia funcional dos maxilares. São Paulo: Editora Santos; 2002. p. 1054.

26. Godolfim, LR. O tratamento do ronco e apnéia do sono com dispositivos intra-orais. Ortodontia. 2002;35(2):87-91.

27. Mehta A, Qian J, Petocz P, Darendeliler MA, Cistulli PA. A randomized, controlled study of a mandibular advancement splint for obstructive sleep apnea. Am J Respir Crit Care Med. 2001;163(6):1457-61. doi: 10.1164/ajrccm.163.6.2004213

28. Mayer G, Meier-Ewert K. Cephalometric predictors for orthopaedic mandibular advancement in obstructive sleep apnoea. Eur J Orthod. 1995;17(1):35-43. doi: 10.1093/ ejo/17.1.35
29. Johal A, Battagel JM. An investigation into the changes in airway dimension and the efficacy of mandibular advancement appliances in subjects with obstructive sleep apnoea. $\mathrm{Br} J$ Orthod. 1999;26(3):205-10.

30. Almeida FR, Lowe AA, Sung JO, Tsuiki S, Otsuka R. Longterm sequellae of oral appliance therapy in obstructive sleep apnea patients: part 1. Cephalometric analysis. Am J Orthod Dentofacial Orthop. 2006a;129(2):195-204. doi:10.1016/j. ajodo.2005.10.001
Received on: 5/12/2012

Final version resubmitted on: 11/6/2013

Approved on: 28/10/2013 
